\title{
Prólogo \\ Lo Público: Un espacio en disputa
}

\author{
Juan Pablo Paredes P. \\ Universidad Diego Portales, Santiago, Chile. Email: juan.paredes@udp.cl \\ Eduardo Thayer V. \\ Universidad de Los Lagos, Santiago, Chile. Email: eduardo.thayer@gmail.com \\ Antonio Elizalde H. \\ Universidad Bolivariana, Santiago, Chile. Email: antonio.elizalde@gmail.com
}

\begin{abstract}
Rastrear los diferentes sentidos de lo público en la historia de la humanidad, es entrar en un terreno marcado por la polémica. Sus raíces y huellas son posibles de encontrar en la polis griega como en la res pública romana. Su fisonomía moderna está marcada, sin duda, por el pensamiento de Inmanuel Kant, quien de alguna manera delimitará el debate, que continuará en las reflexiones seminales de Jurgen Habermas sobre la esfera pública o en la crítica de Hannah Arendt a la distinción entre lo social y lo político. Trabajos que han dado la pauta a un conjunto amplio de reflexiones y que a su vez han generado una serie de respuestas, derivados, revisiones, comentarios y críticas al concepto de lo público, al punto que el debate ha desbordado los márgenes de la teoría política para desplegarse en variadas disciplinas, desde la sociología, el urbanismo, la geografía, la antropología, los estudios culturales y comunicacionales.
\end{abstract}

Hace varias décadas que Richard Sennett publicaba su ya clásico estudio sobre la relación entre el espacio social y el individuo, titulado "El declive del hombre público" (1974). En él desarrolla las diferentes formas en las que se configura el espacio social, en relación a una serie de procesos socioculturales, políticos y económicos, que Sennett focaliza en el advenimiento del capitalismo y el nacimiento de la vida privada. A partir del siglo XVIII Sennett observa un constante deterioro de lo público, en tanto pierde su fuerza vinculante y su relevancia social, culminando en la época contemporánea con su decadencia.

Más de 30 años han pasado desde los análisis de Sennett y el escenario para la discusión sobre el carácter de lo público ha cambiado considerablemente, de manera sistemática y a nivel mundial en los últimos 10 años. Las series de crisis que han golpeado a Medio Oriente, Europa, Norteamérica y Latinoamérica, con sus respectivas respuestas sociales y ciudadanas así lo expresan: crisis económicas (principalmente las series de crisis del modelo de acumulación neoliberal), las crisis políticas (sistemas de democracia de baja intensidad o directamente autoritarios) y las crisis sociales (modelos de sociedades desiguales y altamente discriminadoras), se han vuelto una constante en el contexto de "la modernidad tardía".

Específicamente, en América Latina se ha iniciado una fuerte reflexión en torno a los sentidos de lo público en el mundo académico, como lo detallan las sistemáticas reflexiones y publicaciones de G. Cunill Grau, L. Avritzer, N. Robotnikof, F. Olivera, S. Costa, entre otros/as y por mencionar solo a un grupo destacado de analistas e investigadores/as sociales de esta parte del mundo. Estas reflexiones y estudios sobre lo público, se han acompañado y han sido profundamente estimuladas por una serie de acontecimientos y procesos sociopolíticos e históricos en el subcontinente. Desde los zapatistas a mediados de los 90 y los presupuestos participativos, con sus derivados ciudadanos del Brasil, pasando por lo sucedido en Argentina el 2001, la democracia ciudadana del Uruguay, el Estado plurinacional en Bolivia y actualmente los estudiantes en Chile, se han fomentado acciones que resignifican al espacio público y lo ubican como un preciado objeto de disputa. Por lo mismo la reflexión sobre lo público no solamente desbordó los márgenes disciplinares, desbordó a la propia academia para posicionar el debate más acá de los espacios universitarios. El mejor ejemplo de lo anterior ha sido a lo largo del siglo XX y que se extiende hasta hoy, el movimiento feminista y su cuestionamiento a la diferencia público y privado. 
Una de las principales aristas que abre el párrafo anterior, es indagar en la estrecha relación entre procesos de amplificación- profundización democrática y los sentidos que pueda adquirir lo público. En los procesos de disputa democrática, que se dan en América Latina a partir de la segunda mitad de los 90, el espacio público, sus usos y significados ha sido uno de los objetos más controversiales, debido a la relevancia otorgada por actores sociales y culturales que no participan directamente de las decisiones sobre aquello que es público. En otros términos lo público deviene en sí mismo un espacio de luchas sociales y políticas, que implica otras luchas muy significativas en la actualidad, como son las luchas frente a la desigualdad y la justicia social, por el reconocimiento de la diferencia, por la ciudadanía y la democracia.

Lo público en tanto zona de conflicto sobre los sentidos y las formas de vivir en sociedad, al decir de Robotnikof, alcanzaría así tres aspectos relevantes para su discusión: a) lo público como aquello que es común a todos; b) lo público como aquello que es visible para todos y; c) lo público como aquello que está disponible para todos. Estos tres aspectos llevan consigo la marca de su doble: cómo entender lo privado, lo oculto y lo reservado. Lo público y sus sentidos disputan, a la vez, los sentidos de sus otros.

De este modo, lo público se transforma en la actualidad en el espacio donde las relaciones sociales y sus sentidos se materializan en una orientación democrática. Es el espacio en que las prácticas de los diferentes actores y sujetos, sociales y políticos, se realizan, tanto en sus formas de dominación, como en las de autonomía. Con ello observamos los intentos por superar la obsolescencia de lo público, en tanto redefiniciones de lo común, lo visible y lo disponible a todos. Si aceptamos que lo anterior es válido, la tesis de Sennett sobre la decadencia del espacio público puede ser debatida.

Cuestionar la tesis de Sennett conlleva formular una serie de preguntas, para poder configurar un repertorio de argumentos que nos permitan debatir en profundidad sobre lo público y sus sentidos. Primero, y de manera fundamental, ¿qué entenderemos por lo público?, sobre la premisa de que no existe un acuerdo total sobre tal definición, y con ello preguntamos ¿cómo se configura lo público? Por otro lado y en paralelo, podemos preguntarnos: ¿Cuáles son los procesos y acciones que pueden/deben expresarse en ese espacio? Lo anterior nos pone ante la difícil tarea de delimitar a los actores que pueden tomar parte de eso, en base a la pregunta: ¿quiénes son los actores que participan de lo público?; ¿cómo se define tal participación?; ¿cómo se excluyen a quiénes quedan fuera de la configuración del espacio? Y por supuesto, se abre la reflexión hacia los sentidos de lo otro de lo público: lo privado.

Todas las preguntas anteriores inducen a la polémica, a la diferencia e incluso al desacuerdo, es decir, abren un espacio para la disputa por sus sentidos. Ya que no existe una única ni universal respuesta, al contrario, son respuestas que requieren de su propia formulación pública para ser debatida. Y cada posición deberá enfrentar argumentos de índole empíricos, normativos e históricos, tanto a favor como en contra. En otras palabras el mismo debate sobre lo público es constitutivo de lo que podemos entender por ello.

En lo anterior radica la importancia del número 31 de Polis, que fiel a su nombre y a su preocupación por lo público, intenta abordar algunas de las preguntas formuladas con anterioridad. Las contribuciones de la sección Lente de Aproximación, bajo el título "Lo Público: un espacio en disputa", apuntan a dar sus respuestas, directas en algunos casos u oblicuas en otros, pero todas se orientan a poner en discusión alguna definición de aquello que se entiende por lo público y cuáles son los alcances y límites de tal comprensión.

Abre el Lente de Aproximación de este número el trabajo de Nicolás Angelcos Gutiérrez "Lucha por la vivienda y politización de las trayectorias individuales" quien aborda las formas y mecanismos que adoptan los procesos de politización en los sectores populares chilenos, desarrollando la tesis de la necesidad de problematizar la relación entre subjetivación individual y subjetivación colectiva para comprender la politización de las demandas, en principio instrumentales, que articula el movimiento de lucha por la vivienda y las trayectorias individuales de los vecinos miembros del comité estudiado, buscando responder la pregunta sobre cómo explicar la politización de ciertos individuos en un medio social donde reina la pasividad.

Continúa el artículo "Relación Estado/nación, modelo de desarrollo económico y sistema de partidos en Chile: breve revisión histórica para tratar de entender un cambio de época", en el cual Daniel Bello revisa las etapas por las que transitó el Estado chileno a partir de la década de 1930. Distingue dos etapas, la primera caracterizada por la constitución del Estado en pieza clave del modelo de desarrollo 
económico y de organización de la sociedad. La segunda, a partir del quiebre democrático de 1973, repliega al Estado e impone al mercado como eje central del modelo económico y principal mecanismo de distribución de bienes y servicios. El retorno a la democracia marcado por esta realidad "mercado-céntrica" y por la nueva estructura institucional ideada durante la dictadura militar, moldeó el sistema de partidos y cambió las estrategias de interacción entre partidos políticos y sociedad, privilegiándose el marketing político y el uso de medios de comunicación masivos por sobre la relación directa con las organizaciones sociales.

Luego, "La noción de espacio público y la configuración de la ciudad: fundamentos para los relatos de pérdida, civilidad y disputa" de Berroeta y Tomeu Vidal, revisa las diversas nociones del espacio público en su dimensión comunicativa. En cada época el discurso construyó ciertas ideas del espacio público, donde la infraestructura, la organización social y la situación económica variaron a través de los años. El texto analiza la construcción del espacio público y las relaciones de poder en la época clásica, media, moderna y contemporánea. En ésta última el autor concluye que existen variados discursos y representaciones sobre el espacio público, que lo entienden como perdido, como construcción de civilidad o como lugar de control y disputa.

Mariana Canavese en su artículo "El espacio público entre la asfixia y la resistencia: usos de Foucault durante la dictadura argentina" analiza las formas de circulación, lectura, interpretación y apropiación de las elaboraciones foucaultianas bajo las condiciones impuestas por la última dictadura militar argentina. Busca reconstruir históricamente y analizar esas apropiaciones que se manifestaron en las Ciencias Sociales bajo la hipótesis de que es posible divisar la vitalidad de un espacio público subterráneo que subsistió aun en las peores condiciones de opresión y explorar así usos estratégicos en el ámbito político-intelectual que ampliaban los márgenes de un espacio público sofocado.

El artículo "Políticas de Ciudad: planear la ciudad para reivindicar la dimensión humana" de Lucas Correa Montoya nos invita a pensar y diseñar la ciudad desde unas "políticas" más allá de un punto de vista tradicional y funcionalista. Éstas deben abordarse como un asunto complejo que requiere su consideración ética y humana. Las políticas de ciudad son entendidas por el autor como políticas públicas, donde la relación dialéctica entre las policy y las politics deben ser integradoras y promover decididamente la participación de la ciudadanía en su conjunto, debido a que la ciudad es un espacio complejo que contiene múltiples necesidades, visiones y aspectos.

Carlos Durán Migliardi en su artículo "Multiculturalismo, publicidad y ciudadanía" discute la relación entre publicidad y diferencia sostenida por la política multiculturalista, que apunta a superar la "ficción liberal" de la homogeneidad que destaca la diferencia de patrones culturales como un elemento fundamental en la configuración de un espacio público democrático abierto a la diversidad. El multiculturalismo, junto con ser una categoría indicativa de un determinado estado de "diversidad" característico de sociedades complejas en que orden social y subjetividad aparecen como realidades escindidas, se constituye a su vez en una forma de asumir la configuración de lo público y de la ciudadanía de manera distinta a los principios liberal-individualistas clásicos.

Erazo, Villalta y Morales en "Representaciones sociales del asociativismo municipales en educación: un marco conceptual para la educación chilena" hacen uso de la teoría de las Representaciones Sociales (RS) para analizar los elementos cognitivos y socialmente construidos que sustentan las acciones de gestión micro y macro institucional, y de coordinación entre varias municipalidades de un mismo territorio, estudiando específicamente las representaciones sociales de la asociatividad en el tema educativo, desde actores político-administrativos y profesionales implicados en la mejora de la educación municipal.

En "La dimensión espacial de los conflictos ambientales en Chile", Manuel Fuenzalida y Rodolfo Quiroz se proponen develar el patrón territorial de los conflictos ambientales mediante la construcción de un índice sintético de vulnerabilidad social, con soporte en la unidad de análisis político-administrativa de administración local, junto a la localización de los conflictos ambientales denunciados por ONG's. Este índice permitirá estudiar la relación espacial existente y determinar qué perfil de unidades territoriales soportan mayor carga de externalidades negativas generadas por proyectos de inversión privada. Hará posible también cuantificar los niveles de justicia ambiental en el país. 
Enrique Gallardo, en "Lo público en los procesos comunitarios de los pueblos indígenas en México", describe la organización de las comunidades indígenas mexicanas. Distingue la organización comunitaria y las democracias modernas, como dos organizaciones con procesos políticos diferentes. En la organización comunitaria se encuentra una asamblea respetada, cargos públicos y decisiones singulares, específicos a cada comunidad, sin embargo la pluralidad de modalidades de organización produce que la desinformación del sistema comunitario no permita realizar políticas públicas adecuadas para la construcción de un país multicultural.

"Lo auténtico también es público. Comprensión de lo público desde las clases medias en Chile" es un trabajo de María Luisa Méndez y Emmanuelle Barozet, en el cual con evidencia empírica cualitativa acerca de las clases medias en Chile, analizan el enfoque pesimista de Richard Sennett sobre el futuro de lo público. Se proponen tres claves interpretativas - la intermitencia del paso de lo público a lo privado, las tensiones que se generan entre ambos y finalmente la demanda por autenticidad como forma de apelar a lo público - para entender la articulación entre los espacios públicos y privados en la vida cotidiana. Muestran como la historia reciente de Chile ha obligado a los individuos y las familias a hacerse cargo de lo público, desde lo privado.

En su artículo "Territorios de la memoria: La retórica de la calle en Villa Francia", Gabriela Raposo, aborda la relación entre memoria, identidad y territorio, utilizando como para ello las diversas prácticas conmemorativas post-dictadura que se desarrollan en Villa Francia, barrio emblemático de la ciudad de Santiago. Relación que se traduce en la ocupación de la calle, en tanto territorio donde la memoria se emplaza, a la vez que parte misma de los objetos de memorialización. La ocupación de la calle es producto de encuentros y desencuentros en el tiempo, que involucran tanto los contenidos de memoria, como características materiales y simbólicas de prácticas conmemorativas que se sostienen en el espacio público y que conducen a comprender la calle como el resultado de lo múltiple, de lo deseado y no deseado, fruto de la acción práctica de la identidad en el territorio.

Loreto Rebolledo, en "Resistencia y cambios identitarios en trabajadores/as del salmón en Quellón", da cuenta de algunos procesos de transformación y resistencia cultural expresados en las identidades de trabajadores /as de la industria salmonera, que en los últimos 20 años han sido protagonistas de profundos cambios a nivel personal y colectivo. Analiza en el municipio de Quellón lugar con fuertes tradiciones y una cosmovisión particular fruto del mestizaje español-huilliche, cómo el auge y la crisis de la industria del salmón han puesto en juego la tensión entre elementos de tradición y de modernidad.

En "Lo público y la libertad en el pensamiento de Julien Freund", Cristián Rojas retoma la clásica problemática en la teoría política moderna sobre los espacios de libertad en lo público y lo privado, desde las formulaciones de Julien Freund. El argumento de Rojas es que el espacio público, a diferencia de lo que plantea el liberalismo tradicional, es un espacio de libertad en el ámbito político. Para sustentarlo realiza un detallado examen del concepto de libertad en Freund, además del significado del espacio privado y de la esfera pública. Esta última, en definitiva, cumple la tarea de promover la libertad y su ausencia posibilitaría la emergencia de la tiranía y de sistemas totalitarios.

Gonzalo Sanz Cerbino en su artículo "Burguesía agraria, conflictividad política y quiebres institucionales. Argentina, 1975-2008" realiza una interesante comparación entre los "paros agrarios" de 1975, con los que las corporaciones rurales iniciaron una ofensiva destinada a impulsar el golpe de estado de marzo de 1976 y eliminar así la amenaza revolucionaria para relanzar la acumulación de capital, y los conflictos que enfrentaron a la burguesía agraria argentina con el gobierno nacional encabezado por Cristina Fernández de Kirchner, entre marzo y julio de 2008. Se buscan las alianzas sociales enfrentadas en ambas coyunturas, sus componentes, sus programas y sus acciones, prestando especial atención a la acción política emprendida por la burguesía agraria.

Finalmente, en "Las promesas de la modernidad puestas en juego: el sometimiento de la autonomía colectiva a libertad individual en el Mercado", Beatriz Silva Pinochet, señala que el proyecto de modernidad actualmente confronta dos visiones de libertad que han estado presentes durante la Era Moderna, la libertad individual - que en este caso se manifiesta exclusivamente como acción en el mercado- y la autonomía colectiva. Ambas han producido experimentos para establecer la soberanía del pueblo 
(socialismo) así como para someter totalmente la democracia a la acción individual, eliminando toda posibilidad de autonomía colectiva. Es este último el experimento en que nos encontramos hoy, el cual aunque ha recibido innumerables críticas sigue manteniendo su predominio a nivel mundial.

A continuación la sección Cartografías para el Futuro presenta el artículo de Carlos Walter PortoGonçalves y Pedro de Araújo Quental, “América Latina e a Colonialidade do Poder”, en que cuestionan la lógica territorial vigente en los procesos de integración regional en curso hoy en América Latina que concibe grandes áreas del espacio geográfico en América Latina como "vacíos demográficos" o como "tierras disponibles". Esta concepción del territorio latinoamericano se remonta a la herencia colonial que atraviesa la formación socio-espacial de la región y la propia posición que el continente americano ocupó en el proceso de formación del sistema-mundo moderno-colonial, a partir de 1492. El artículo problematiza los procesos de integración física en curso en el continente, en particular la Iniciativa para la Integración de la Infraestructura Regional Suramericana (IIRSA) y pone en evidencia la reproducción de la lógica de la colonialidad del poder y del saber constituyentes de su modelo de desarrollo regional.

En la sección Proyectos y Avances de Investigación se presentan artículos de: Héctor Berroeta Torres, Fuad Hatibovic Díaz y Domingo Asún Salazar, "Psicología Comunitaria: prácticas en Valparaíso y visión disciplinar de los académicos nacionales"; de Noelia Carrasco, "Trayectoria de las relaciones entre empresas forestales y comunidades mapuche en Chile. Aportes para la reconstrucción etnográfica del desarrollo económico en contextos interétnicos"; de Ignacio Madero Cabib y Juan Carlos Castillo, "Sobre el estudio empírico de la solidaridad: aproximaciones conceptuales y metodológicas"; de Alberto Díaz Araya, Carlos Mondaca Rojas, Claudio Aguirre Munizaga y Jorge Said Barahona, "Nación y ritualidad en el desierto chileno. Representaciones y discursos nacionales en Iquique (1900 - 1930)", de José Olavarría y Rodrigo Molina, "Embarazos en adolescentes, vulnerabilidades y políticas públicas"; de Guillermo Rojas Trujillo, "Interculturalidad y pedagogía diferenciada: senderos compartidos"; de Ximena Valdés Subercaseaux, "Desincronización temporal y espacial entre trabajo y familia: Hacerse el salario en las migraciones estacionales de los/as temporeros/as de la uva"; de Marco Valencia Palacios y Cecilia Muñoz Zúñiga, “La Elite del Conocimiento en la Sociedad Moderna: Intelectuales, Científicos y Profesionales"; y de Luis Iván Valenzuela Espinoza, "Complejidad, globalización y teoría social".

La sección Reseñas incluye seis en este número. De María Gabriela Córdoba del libro La construcción social del sujeto migrante en América Latina. Prácticas, representaciones y categorías de Bela FeldmanBianco, Liliana Rivera Sánchez, Carolina Stefoni y Marta Inés Villa Martínez (eds.); de Hernán Cuevas Valenzuela del libro En el Nombre del Pueblo: la emergencia del populismo kirchnerista de Paula Biglieri y Gloria Perelló (eds.); de Hernán Dinamarca del libro Múltiples identidades de Verena Dolle (ed.); de Antonio Elizalde del libro La revolución capitalista en Chile (1973-2003) de Manuel Gárate Chateau; de Daniella Gac Jiménez del libro Sentido de pertenencia de sociedades fragmentadas. América Latina desde una perspectiva global de Martín Hopenhayn y Ana Sojo (comps.); y de Ricardo Jiménez del libro Madres e hijos/as de locutorio de Lucía Alvites.

Este número concluye con una entrevista a Ernesto Laclau realizada por Hernán Cuevas Valenzuela y Juan Pablo Paredes. 